\title{
Adsorption and recovery of aroma compounds from wastewater of clove oil distillation using coffee husk biosorbent
}

\author{
Askal Maimulyanti $^{\mathrm{a}, *}$, Anton Restu Prihadi ${ }^{\mathrm{b}}$, Tita Rosita ${ }^{\mathrm{c}}$, Iwan Safrudin ${ }^{\mathrm{d}}$ \\ ${ }^{a}$ Department of Analytical Chemistry, Politeknik AKA Bogor, Indonesia \\ b Department of Food Industrial Quality Assurance, Politeknik AKA Bogor, Indonesia \\ c Statistics Group, Department of Analytical Chemistry, Politeknik AKA Bogor, Indonesia \\ d Department of R\&D, PT. Indesso Aroma, Cibubur-Cileungsi, Indonesia
}

*Corresponding author, e-mail: askal_m@yahoo.com

\begin{abstract}
Coffee husk was used as potential biosorbent in order to adsorb volatile compounds from wastewater of clove oil distillation and the oil was recovered from the wastewater. Fourier-transform infrared spectroscopy (FTIR) and scanning electron microscopy (SEM) were used for the characterization of coffee husk. Coffee husk was carbonized and activated using hydrochloric acid. Identification of functional group by infrared spectrum on coffee husk showed the dominant peaks at $3327 \mathrm{~cm}^{-1}(\mathrm{O}-\mathrm{H})$ and $1608 \mathrm{~cm}^{-1}(\mathrm{C}=\mathrm{C}, \mathrm{C}=\mathrm{O})$. The activated carbonized coffee husk showed the $\mathrm{OH}$-peaks weakly in the spectrum. SEM surface analysis showed an uneven surface on the coffee husk. The optimum adsorption of clove oil was determined by chemical oxygen demand (COD). Optimization of coffee husk adsorbent was obtained by waste volume of $10 \mathrm{ml}$, the weight of $1.5 \mathrm{~g}$ and contact time of $120 \mathrm{~min}$. The adsorption efficiency of the organic compound from wastewater was $37.96 \%$. Eugenol and eugenol acetate recovery of coffee husk adsorption were $79.44 \%$ and $54.05 \%$, respectively. The recovery of clove oil in wastewater distillation was $0.31 \%$.
\end{abstract}

KEYWORDS: Adsorption, aroma compound, clove oil, coffee husk, biosorbent

\section{INTRODUCTION}

Essential oil represents a small fraction of the plant's composition but confers the characteristic for which aromatic plants are used in the pharmaceutical, food and fragrance industries. Essential oils have a complex composition, containing from a few dozen to several hundred constituents, especially hydrocarbons (terpenes and sesquiterpenes) and oxygenated compounds. They are responsible for the characteristic odors and flavor. Steam distillation has traditionally been applied for essential oils recovery from plant materials ${ }^{1}$. Organic compounds are usually determined by using chromatographic techniques, the specific choice depending on their polarity, volatility and their risk of decomposition at high temperature.

Adsorption of organic solutes from aqueous phase is an important application of powdered and granular activated carbons. The characteristic of carbon that affects the adsorption process is the pore texture and surface mineral contact. The adsorption capacity of carbon materials is not related in a simple form with their surface area and porosity.
However, it depends on the accessibility of the organic molecules to the inner surface of the adsorbent which depends on their size. Activated carbon fibers have received increasing attention in recent years as a better adsorbent than granular activated carbons because they normally present much higher adsorption kinetics and adsorption capacity. The surface chemistry of activated carbons essentially depends on their heteroatom content, mainly on their surface oxygen complex content ${ }^{2}$.

Microextraction has been used in the adsorption of a volatile component from natural grass ${ }^{3}$. Solid-phase extraction technique (SPE) involving adsorbents is nowadays extensively employed in the various industrial process, for example, purification, separation and recovery. The essential forces of adsorption are physical in nature so that the physical and chemical properties of adsorbent compounds are not affected. Different types of sorbents have been used in the industrial application e.g. zeolite, alumina, silica and activated carbon. The SPE technique plays an important role in the isolation and recovery of volatile food flavor components ${ }^{4}$. 
Adsorption has been shown to be the most promising option for all these non-biodegradable organics for the removal from aqueous streams. Activated carbons are usually obtained from materials with high carbon content and possess a great adsorption capacity which is mainly determined by their porous structure. Although activated carbon, in granular or powdered form, has a good capacity for the adsorption of organic molecules, it suffers from a number of disadvantages ${ }^{5}$. Active carbon was used in the adsorption of phenolic ${ }^{6}$. The application of activated carbon in the essential oil extraction industry seems scarce. Essential oils are highly concentrated flavoring agents. They are extracted from aromatic plants, mainly by the stream or water distillation. Adsorption of an adsorbate by adsorbents should be described in two aspects: adsorption capacity and affinity. Adsorption capacity is limited by the potential space of a sorbent available for adsorption of given adsorbate while adsorption affinity is dependent on the strength of attractive forces between adsorbate and adsorbent ${ }^{7}$.

The adsorption phenomena depends on the interaction between the surface of the adsorbent and the adsorbed species. The interaction may be due to chemical bonding, hydrogen bonding, hydrophobic bonding, and van der Waal's force. Adsorption process by biosorbent coffee husk has been studied for removal of $\mathrm{Cr}^{6+}$, adsorb of Cd by coffee grounds ${ }^{8,9}$, sorption of $\mathrm{Cu}^{2+}, \mathrm{Pb}^{2+}$ by spent coffee grains, sorption of $\mathrm{Cd}^{2+}$ and $\mathrm{Cr}^{6+}$ by coffee husk ${ }^{10-12}$. There was a limited study about biosorbent of coffee husk to adsorb organic compounds as the volatile aroma from the essential oil.

In this study, we will explore the utilities of the coffee husk as biosorbent to adsorb volatile compounds from wastewater distillation. The volatile compounds consisting of clove oil was adsorbed by the coffee husk, and then it was recovered from the biosorbent. We use coffee husk as biosorbent because it is not expensive, has functionoal group as an active part, has high affinity and be able to use as waste. The aim of this study was to adsorb and recovery of aroma compounds from wastewater distillation of clove oil using biosorbent.

\section{MATERIALS AND METHODS}

\section{Plant materials}

Arabica coffee husks were collected from Pangalengan, West Java, Indonesia. The coffee husks were washed and dried in an oven. The dried coffee husk was crushed by crusher until the particle size passes through a sieve of 18 mesh or about $1 \mathrm{~mm}$. Clove bud (Syzigium aromaticum) was provided from the private plantation in West Java, Indonesia. Clove buds were air-dried prior to hydrodistillation.

\section{Coffee husks biosorbent preparation}

The activated carbon of coffee husks was produced with a slight modification using standard methods of Ekpete $^{13}$. The dried and ground coffee husks were carbonized and activated with $0.1 \mathrm{~N} \mathrm{HCl}$ solution for $5 \mathrm{~h}$, washed with distilled water until a neutral $\mathrm{pH}$ was obtained. Activated carbon of coffee husk was oven-dried at a temperature of $100^{\circ} \mathrm{C}$ for $12 \mathrm{~h}$.

\section{Characterization of coffee husk biosorbent}

The functional groups of the coffee husk, carbonized coffee husk, and activated carbon of coffee husk were characterized by using FTIR and the biosorbent surface was identified by SEM.

\section{Gas chromatography-mass spectrometry (GC-MS) analysis of chemical constituents of clove oil}

Whole clove buds $200 \mathrm{~g}$ were distilled by hydrodistillation using Clevenger-apparatus. Distillation was carried out for $12 \mathrm{~h}$. The oil was collected and stored in a closed dark bottle. Clove bud oil was analyzed by GC-MS Agilent HP7890 GC System, Agilent 5975C series GC MSD. GC 7890 with FID detector, FID heater $275^{\circ} \mathrm{C}$, column Agilent HP-1 methyl siloxane $(30 \mathrm{~m} \times 250 \mu \mathrm{m} \times 0.25 \mu \mathrm{m}$ film thickness), carrier gas Helium with pressure 2.0244 psi; inlet : split ratio $500: 1$, total flow $53.1 \mathrm{ml} / \mathrm{min}$, septum purge flow $3 \mathrm{ml} / \mathrm{min}$, gas saver on $20 \mathrm{ml} / \mathrm{min}$ after 2 min. The oven temperature was programmed from $100^{\circ} \mathrm{C}$ for $10 \mathrm{~min}$, then $5^{\circ} \mathrm{C} / \mathrm{min}$ to $200^{\circ} \mathrm{C}$ for 0 min, then $10^{\circ} \mathrm{C} / \mathrm{min}$ for $10 \mathrm{~min}$, the total running time was $45 \mathrm{~min}$. MS Acquisition parameters : EMV mode was relative, relative voltage was 0 , resulting EM voltage was 2506; scan parameters : low mass 30.0, high mass 500.0, threshold 50; MS zones : MS Source $250^{\circ} \mathrm{C}$ and MS quadrupole $200^{\circ} \mathrm{C}$, ionization voltage $70 \mathrm{eV}$, MSD transfer line $300^{\circ} \mathrm{C}$. Compound identification was done by comparing the Wiley 2008-NIST library and P. Adam data of the peaks with those reported in literature ${ }^{14}$.

\section{Variation of adsorbent weight in adsorption process}

The adsorption process was done by column chromatography. The variation of adsorbent weight was $0.5-2 \mathrm{~g}$. A total of $10 \mathrm{ml}$ of solution was added into the column containing coffee husk biosorbent. The 
solution was allowed to contact with coffee husk adsorbent and was collected from the column.

\section{Effect of contact time in adsorption process}

The clove oil adsorption process was done by column chromatography. The volume of a $10 \mathrm{ml}$ solution was introduced into a column containing coffee husk biosorbent with weight of $0.5 \mathrm{~g}$. The solution was allowed to contact with biosorbent for 30-180 min and the solution was removed from the coffee husk. The chemical oxygen demand (COD) level of solution was measured after the adsorption process on biosorbent coffee husk.

\section{Effect of volume to adsorption of organic compounds}

Clove oil in wastewater was absorbed by activated carbon of coffee husk on column chromatography. The wastewater volume was varied from $10-25 \mathrm{ml}$. The sample was added into a column containing 0.5 $\mathrm{g}$ activated coffee husk biosorbent. The solution was allowed to contact and was removed from adsorbent. The solution obtained from the adsorption process was measured by COD content analysis.

\section{Determination of COD content on samples}

COD is the amount of oxygen needed to break down organic and inorganic compounds in 11 of chemical samples. The determination of COD was carried out by the oxidation process using oxidation of $\mathrm{K}_{2} \mathrm{Cr}_{2} \mathrm{O}_{7}$. This chemical oxidation reaction will oxidize organic substances that cannot be oxidized perfectly such as cellulose. The principle is that most of the organic compounds in water can be oxidized by boiling water that has been added chromate and sulfuric acid. After destruction, the remaining unused potassium dichromate was titrated with a ferrous ammonium sulfate solution to determine the amount of dichromate used to oxidize the organic material. A total of $2.5 \mathrm{ml}$ of sample was added into the reflux apparatus with boiling stones, and then $10 \mathrm{ml}$ of potassium dichromate $0.25 \mathrm{~N}$ and sulfuricsilver sulfuric acid was added into the solution. The solution should be mixed and the heat evenly distributed by slowly and carefully shaking to prevent evaporation. Poured $15 \mathrm{ml}$ of sulfuric acid solutionsulfate pellet through condenser into erlenmeyer flask and shaken gently. The heater and reflux turned on for about $2 \mathrm{~h}$. After the oxidation process finished, let the reflux glass cooled first then rinsed the condenser with distilled water as much as 25$50 \mathrm{ml}$. Added ferroin indicator and titrated with the
Table 1 Identification of adsorbent IR spectrum.

\begin{tabular}{|c|c|c|}
\hline No & Adsorbent & Wavelength $\left(\mathrm{cm}^{-1}\right)$ \\
\hline 1 & Coffee husk & $\begin{array}{l}\text { 3270.36; 2922.89; 2111.96; 1608.87; } \\
\text { 1373.47; 1317.07; 1244.77; 1022.72; } \\
\text { 818.22; 770.54; 610.58; 559.59 }\end{array}$ \\
\hline 2 & $\begin{array}{l}\text { Carbonized of } \\
\text { coffee husk }\end{array}$ & $\begin{array}{l}\text { 3333.98; 2922.90; 2113.57; 1581.05; } \\
\text { 1373.57; 755.05; 611.10; 561.08 }\end{array}$ \\
\hline 3 & $\begin{array}{l}\text { Activated carbon } \\
\text { of coffee husk }\end{array}$ & $\begin{array}{l}\text { 2915.21; 1588.10; 1212.39; 749.47; } \\
566.80\end{array}$ \\
\hline
\end{tabular}

Table 2 Chemical composition of clove oil by GC-MS.

\begin{tabular}{lcrl}
\hline $\begin{array}{l}\text { No } \\
\text { time (min) }\end{array}$ & $\begin{array}{r}\text { Retention } \\
(\%)\end{array}$ & $\begin{array}{r}\text { Composition } \\
\text { timpound }\end{array}$ \\
\hline 1 & 16.164 & 80.26 & Eugenol \\
2 & 17.482 & 0.25 & Q-copaene \\
3 & 18.816 & 5.16 & Caryophyllene \\
4 & 19.805 & 0.84 & $\alpha$-humulene \\
5 & 21.058 & 8.64 & Eugenol acetate \\
6 & 21.587 & 0.15 & Calamenene \\
7 & 23.111 & 0.52 & $\beta$ carrophyllene epoxide \\
8 & 26.287 & 0.17 & Cinnamaldehydemethoxy \\
9 & 38.328 & 0.26 & Benzothiophene \\
\hline
\end{tabular}

standard solution of ferroammonium sulfate 0.002 $\mathrm{N}$ until the green-blue color becomes red brown.

$$
\operatorname{COD}(\mathrm{mg} / \mathrm{l})=\frac{(A-B) \times N \times 8 \times 10^{3}}{\text { Volume of sample }},
$$

$A, \mathrm{ml}$ of ferroammonium sulfate used for the titration of blanks; $B, \mathrm{ml}$ of ferroammonium sulfate used for the titration of the sample; and $N$, normality of ferroammonium sulfate.

\section{Recovery of organic compounds}

The organic compound was recovered by dissolving the adsorbent into ethanol 95\% (v/v) for 60 min. After that, the solution was filtered and preconcentrated using evaporator. The obtained filtrate was tested for chemical composition by GC-MS.

\section{RESULTS AND DISCUSSION}

The identification of molecular species and determination of their concentrations in the sample is an essential part of infrared (IR) spectroscopic analysis $^{15}$.

IR spectra have been used to characterize coffee husk in the region of $3200-3800 \mathrm{~cm}^{-1}$ corresponding to $\mathrm{VOH}$ stretching in a functional group of coffee husks. The adsorption of compounds in the infrared (IR) region to identify functional groups was shown in Fig. 1. The IR spectrum of the dried coffee husk was tested and compared to carbonized coffee husk 
(a)

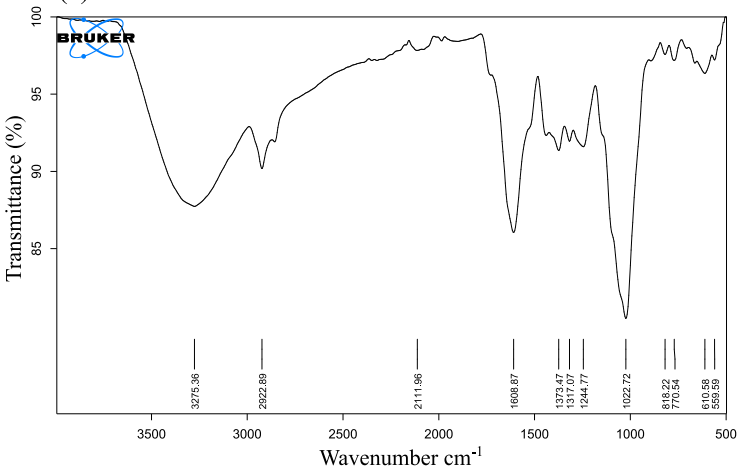

(b)

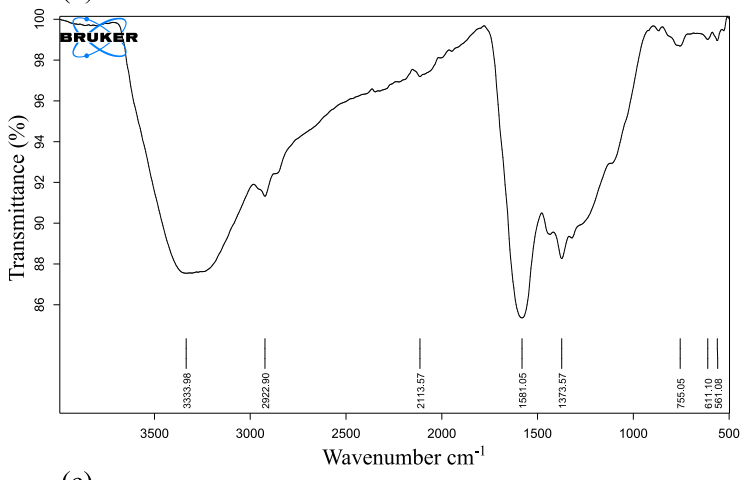

(c)

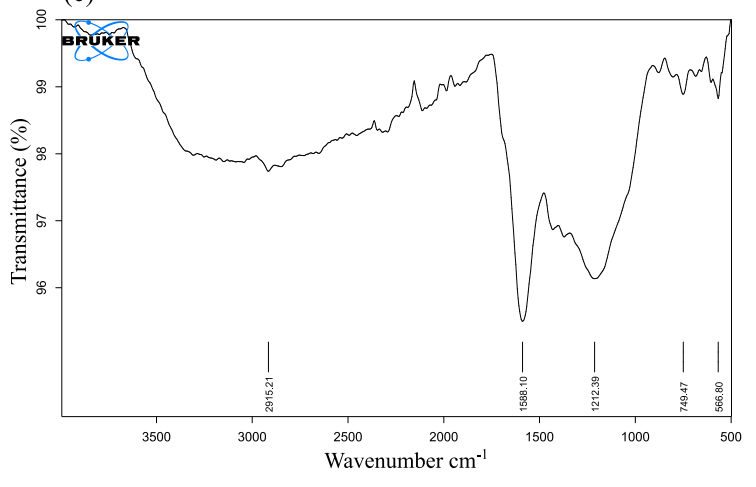

Fig. 1 IR spectrum: (a) coffee husk, (b) carbonized coffee husk, and (c) activated carbon of coffee husk.

and activated carbon of coffee husk (Table 1). In the dried coffee husk, the pattern of the spectrum is relatively similar to the carbonized coffee husk with a widened peak in the area of $3000 \mathrm{~cm}^{-1}$. But after activation, the peak $3000 \mathrm{~cm}^{-1}$ did not appear clearly but generally still showed peaks at the wave number $1000-1500 \mathrm{~cm}^{-1}$. All molecule is made up of atoms linked by chemical bonds. The movement of atoms and the chemical bond can be compared with that of a system comprised of spring and balls in constant motion. Their motion can be understood as being composed of two components, the stretch-
Table 3 Chemical composition (\%) of clove oil by GC-MS after biosorption.

\begin{tabular}{lrrl}
\hline $\begin{array}{l}\text { No } \\
\text { time (min) }\end{array}$ & $\begin{array}{l}\text { Retention } \\
\text { time }\end{array}$ & Compound \\
\hline 1 & 6.195 & 0.34 & a-methylcycloxane \\
2 & 7.288 & 0.29 & n-hexylmethylamine \\
3 & 9.411 & 0.27 & Northiaden \\
4 & 9.508 & 0.29 & 12-(methylamino)dodecanoic \\
5 & 15.904 & 63.76 & Eugenol \\
6 & 21.020 & 4.67 & Eugenol acetate \\
7 & 24.963 & 0.29 & 3-phenyl-piperidine \\
8 & 34.077 & 0.45 & 1,2-Bis (trimethylsilyl) benzene \\
9 & 34.854 & 0.54 & Tetrasiloxane \\
\hline
\end{tabular}

Table 4 Recovery (\%) of clove oil components (\%).

\begin{tabular}{llcccc}
\hline No & Clove Oil & Eugenol & Recovery & $\begin{array}{c}\text { Eugenol } \\
\text { acetate }\end{array}$ & Recovery \\
\hline 1 & from distillation & 80.26 & - & 8.64 & - \\
2 & after adsorption & 63.76 & 79.44 & 4.67 & 54.05 \\
\hline
\end{tabular}

ing and bending vibration. The frequencies of these vibrations depend on the nature of the particular bonds, such as $\mathrm{C}-\mathrm{H} / \mathrm{C}-\mathrm{O}$ bonds ${ }^{16}$. The functional group of coffee husk consisting of $\mathrm{O}-\mathrm{H}, \mathrm{C}-\mathrm{H}$, and $\mathrm{C}=\mathrm{O}$, made the chemical bond with organic volatile compounds when they interacted. The activated carbon of coffee husk with $\mathrm{C}-\mathrm{C}$ and $\mathrm{C}-\mathrm{H}$ have van der Waals interaction with organic compounds.

IR spectroscopy has been the method of choice for studying various issues concerning structure of the molecule ${ }^{16}$. The qualitative aspects of infrared spectroscopy are one of the most powerful attributes of the analytical technique. This is achieved by recognizing characteristic shapes and pattern within the spectrum and by applying the information obtained from the published groups frequently data, along with other chemical and physical data from the sample ${ }^{17}$. Coffee husk contained hydrogenbound $\mathrm{O}-\mathrm{H}$ groups because of their wide peaks that normally appear in the region of about $3000 \mathrm{~cm}^{-1}$. The usual $\mathrm{C}=\mathrm{C}, \mathrm{C}=\mathrm{N}$ clusters appear at $2550-1650$ $\mathrm{cm}^{-1}$. The usual $\mathrm{C}=\mathrm{O}, \mathrm{N}=\mathrm{O}, \mathrm{S}=\mathrm{O}$ groups appear in the $1000 \mathrm{~cm}^{-1}$ region.

The saturated hydrocarbon $\mathrm{C}-\mathrm{H}$ stretching vibration occurs below $3000 \mathrm{~cm}^{-1}$. Any band structures observed between $3150 \mathrm{~cm}^{-1}$ and $3000 \mathrm{~cm}^{-1}$ are almost exclusively indicative of unsaturation $(\mathrm{C}=\mathrm{C}-\mathrm{H})$. The unsaturated hydrocarbons featuring $\mathrm{C}=\mathrm{C}$, with attached hydrogen, usually occur as either a single or pair adsorption. The carbonized coffee husks contain hydrogen-bound $\mathrm{O}-\mathrm{H}$ groups, $\mathrm{C}-\mathrm{H}, \mathrm{C}=\mathrm{C}, \mathrm{C}=\mathrm{N}$ groups in the $1550-1650 \mathrm{~cm}^{-1}$ and 


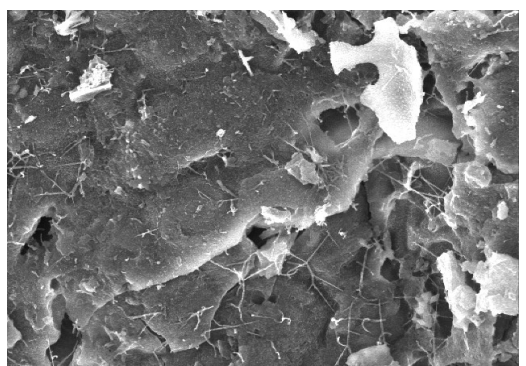

(a)

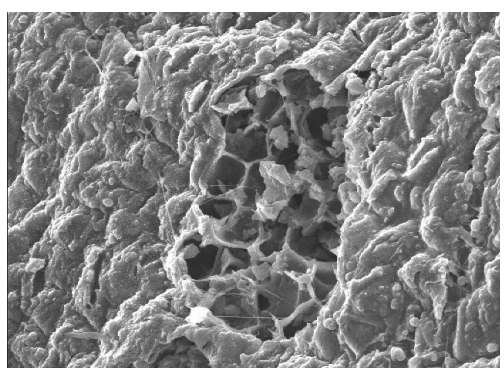

(b)

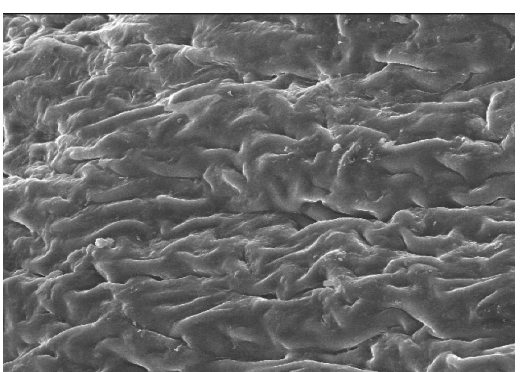

(c)

Fig. 2 SEM analysis: (a) carbonized coffee husk, (b) activated coffee husk carbon, and (c) activated carbon after adsorption.
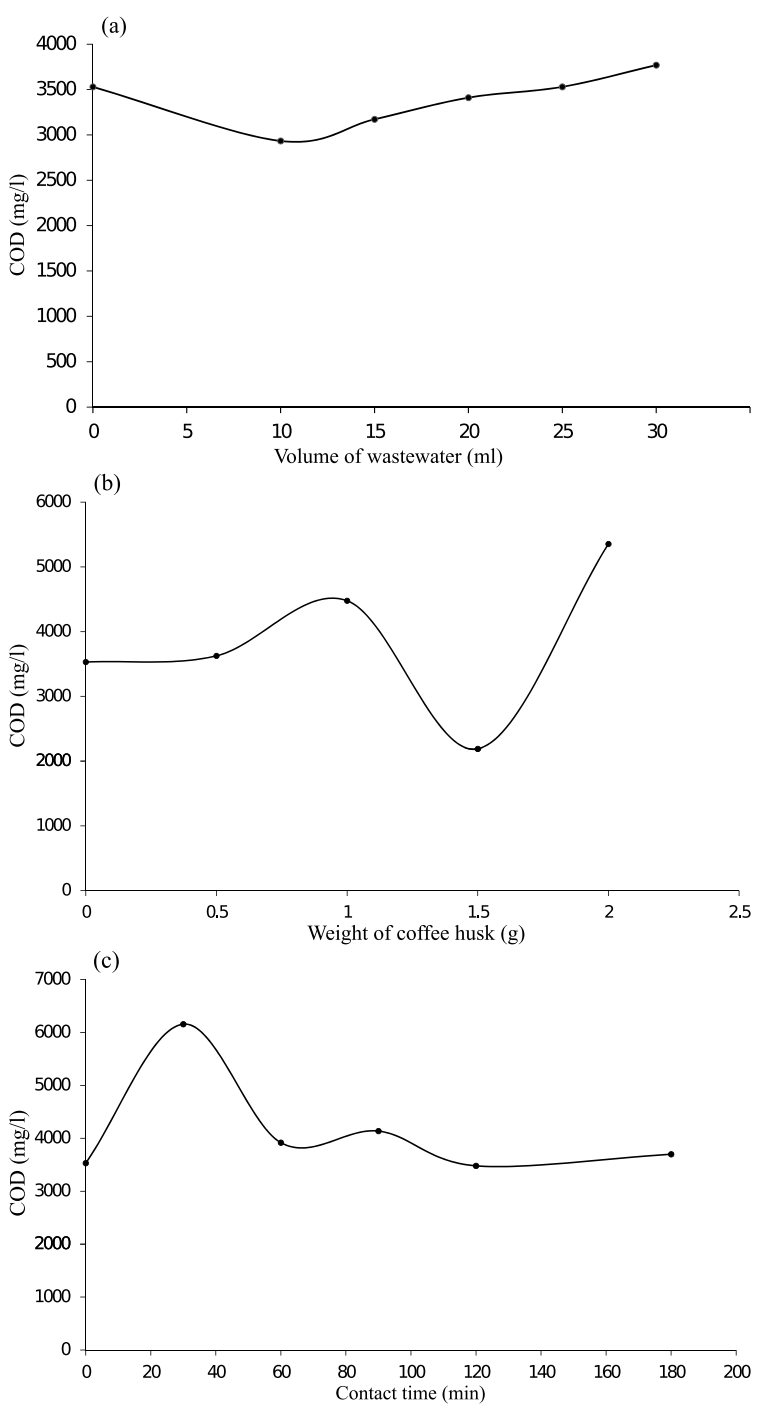

Fig. 3 Effect of parameters on coffee husk adsorption against COD content: (a) volume, (b) weight of activated carbon, and (c) contact time. sulfonamide peaks, $\mathrm{C}-\mathrm{O}$ and $\mathrm{N}=\mathrm{O}$ at $1373 \mathrm{~cm}^{-1}$. The hydroxyl function is probably one of the most dominant and characteristic of all of the infrared group frequencies. The $\mathrm{OH}$ bending vibration is broadened by hydrogen bonding as the stretching vibration ${ }^{18}$.

The surface analysis of the adsorbent was identified by SEM (Fig. 2). The SEM analysis showed the differences of the surface between carbonized coffee husk, activated carbon of coffee, and activated carbon after the adsorption process. The coffee husk that was nested indicated an active part of the pore with relatively large size. After the activation process with acid, the surface of the coated coffee was more reactive indicating that the surface had more pore. Activated coffee husk carbon that adsorbed organic compounds showed a more enclosed surface indicating that there has been adsorption of organic compounds on the surface of the activated pores.

Fig. 3 shows the decrease in the value of COD at the volume of waste $10 \mathrm{ml}$. The optimum adsorption was obtained at $10 \mathrm{ml}$ waste volume with the COD value of $2934.3 \mathrm{mg} / \mathrm{l}$. Variations of adsorbent weight were tested for absorption of $10 \mathrm{ml}$ of waste. The optimum weight of coffee husk to absorb waste was $1.5 \mathrm{~g}$ with COD value of $2190.2 \mathrm{mg} / \mathrm{l}$. The effect of contact time on the adsorption process was shown by the COD value of clove oil waste. The value of COD increased for a contact time of $30 \mathrm{~min}$. After 30 min of contact time, COD levels were relatively stable with optimum conditions at 120 min with COD value of $3480 \mathrm{mg} / \mathrm{l}$.

The main components of clove oil obtained by hydrodistillation were analyzed by GC-MS (Table 2). The main compounds of clove oil were eugenol $(80.26 \%)$, eugenol acetate $(8.64 \%)$ and caryophyllene $(5.16 \%)$. The main components of clove oil after adsorption on the coffee husk of eugenol, eugenol acetate and tetrasiloxane with 
composition of $63.76,4.67$, and $0.54 \%$, respectively, were observed (Table 3 ). The main composition after adsorption on coffee husk was shown in Table 4. The data showed oil adsorption as eugenol recovery on coffee husk adsorbent was $79.44 \%$ and eugenol acetate compound was $54.05 \%$ with a recovery value of oil was $0.31 \%$.

Acknowledgements: This research received financial support from project research SPIRIT 2018, Pusdiklat Industri Ministry of Industry, Indonesia.

\section{REFERENCES}

1. Pourmortazaui SM, Hajinirsaddeghi SS (2007) Supercritical fluid extraction in plant essential and volatile oil analysis. J Chromatogr A 1163, 2-24.

2. Moresnocastilla C (2004) Adsorption of organic molecules from aqueous solution on carbon materials. Carbon 42, 83-94.

3. Cornu A, Carna AP, Martin B, Coulon JP, Lamaison JL, Berdaque JL (2001) Solid-phase microextraction of volatile components from natural grassland plants. $J$ Agr Food Chem 49, 203-209.

4. Edris AE, Girgis BS, Fadel HHM (2003) Recovery of volatile aroma components from aqueous waste streams using an activated carbon column. Food Chem 82, 195-202.

5. Aksu Z (2005) Application of biosorption for the removal of organic pollutants: a review. Process Biochem 40, 997-1026.

6. Dabrowski A, Podkoscielny P, Hubicki Z, Barezak M (2005) Adsorption of phenolic compounds by activated carbon-a critical review. Chemosphere 58, 1049-1070.

7. Yang K, Xing B (2010) Adsorption of organic compounds by carbon nanomaterials in phase: Polanyi theory and its application. Chem Rev 110, 5989-6008.
8. Parida SK, Dash S, Patel S, Misha BK (2006) Adsorption of organic molecules on silica surface. $A d v$ Colloid Interface Sci 121, 77-110.

9. Ahalya N, Kanamadi RD, Ramachandra TV (2010) Removal of hexavalent chromium using coffee husk. Int $J$ Environ Pollut 43, 106-116.

10. Azouaou N, Sadaoui Z, Djaafri A, Mokaddem H (2010) Adsorption of cadmium from aqueous solution onto untreated coffee grounds: Equilibrium, kinetic and thermodynamics. J Hazard Mater 184, 126-134.

11. Cerinocordova FJ, Diaz-Flores PE, Garcia-Reyes RB, Sotoregalado E, Gomez-Gonzales R, Garzagonzdez MT, Bustamante-Alcantara E (2013) Biosorption of $\mathrm{Cu}$ (II) and $\mathrm{Pb}$ (II) from aqueous solution by chemically modified spent coffee grains. Int $J$ Environ Sci Technol 10, 611-622.

12. Zakaria A, Maimulyanti A, Prihadi AR, Nurhasanah, Djasmasari A (2017) Adsorption capacity of $\mathrm{Pb}(\mathrm{II})$, $\mathrm{Cd}(\mathrm{II})$, and $\mathrm{Cr}(\mathrm{VI})$ from aqueous solution using coffee industry waste. J Chem Pharm Res 9, 81-87.

13. Ekpete OA, Marcus AC, Osi V (2017) Preparation and characterization of activated carbon obtained from plantain (Musa paradisiaca) fruit stem. J Chem 2017, ID 8635615.

14. Safrudin I, Maimulyanti A, Prihadi AR (2015) Effect of crushing of clove bud (Syzigium aromaticum) and distillation rate on main constituents of the essential oil. Am J Essent Oil Nat Prod 2, 12-15.

15. Bacsik Z, Mink J, Keresztury G (2004) FTIR spectroscopy of the atmosphere, principles and methods. Appl Spectrosc Rev 39, 295-363.

16. Mehrotra R (2000) Infrared Spectroscopy, Gas Chromatography/Infrared in Food Analysis, Encyclopedia of Analytical Chemistry, John Willey \& Sons, USA.

17. Banyay M, Sarkar M, Graslund A (2003) A Library of IR Band of nucleic acids in solution. Biophys Chem 104, 477-488.

18. Coates J (2006) A Practical Approach, Encyclopedia of Analytical Chemistry, John Wiley \& Sons, USA. 